\title{
Dimensionless curves of centrifugal pumps for water supply systems: development and case study
}

\section{Curvas adimensionais de bombas centrífugas para sistemas de abastecimento de água: desenvolvimento e estudo de caso}

\author{
Jóice Cristini Kuritza ${ }^{1}$, Giovani Camponogara ${ }^{1}$, Marcelo Giulian Marques ${ }^{1}$, \\ Daniela Guzzon Sanagiotto ${ }^{1}$ and Cristiane Battiston ${ }^{2}$ \\ ${ }^{1}$ Universidade Federal do Rio Grande do Sul, Porto Alegre, RS, Brazil \\ ${ }^{2}$ Ministério do Planejamento, Governo Federal, Brasília, DF, Brazil \\ E-mails: joicekuritza@gmail.com (JCK), giovani_camponogara@hotmail.com (GC),mmarques@iph.ufrgs.br (MGM), \\ dsanagiotto@ufrgs.br (DGS), cbattiston@gmail.com (CB)
}

Received: February 01, 2017 - Revised: May 03, 2017 - Accepted: May 17, 2017

\begin{abstract}
Centrifugal pumps are widely used in water supply systems and account for more than $90 \%$ of the electricity consumption of water pumping stations. Studies that seek to generalize the characterization of performance curves of centrifugal pumps are extremely useful. A study was carried out on the dimensionless characteristics of the operating conditions of centrifugal pumps for preliminary design estimations of water supply systems aiming at energy efficiency. The research consisted of the analysis of performance curves of centrifugal pumps from which data was collected regarding the point of maximum yield (PMY). The curves and the equations obtained were made dimensionless so that the information could be extrapolated to other situations. A case study was conducted in the Water Supply System of Vale Campus of the Federal University of Rio Grande do Sul (UFRGS) to demonstrate the application of those equations and curves developed. The dimensionless equations were useful to determine which discharge should be adopted so that the system would be more efficient hydro and energetically and, also, to determine how much more energy would be consumed in the case of alteration of the point of operation of the pump by a throttling valve.
\end{abstract}

Keywords: Centrifugal pumps; Energy efficiency; Maximum yield; Dimensionless curves.

\section{RESUMO}

As bombas centrífugas são amplamente utilizadas em sistemas de abastecimento de água e o seu funcionamento é responsável por mais de $90 \%$ do consumo de energia elétrica das estações de bombeamento de água. Estudos que busquem generalizar a caracterização das curvas de desempenho de bombas centrífugas são extremamente úteis. Realizou-se um estudo sobre as características adimensionais das condições de operação de bombas centrífugas para estimativas prévias de projetos de sistemas de abastecimento de água visando à eficiência energética. $\mathrm{O}$ trabalho consistiu na análise de curvas de desempenho de bombas centrífugas das quais foram extraídas informações sobre o ponto de máximo rendimento (PMR). As curvas e as equações obtidas foram adimensionalizados de modo que as informações pudessem ser extrapoladas para outras situações. Foi realizado um estudo de caso no Sistema de Abastecimento de Água do Campus do Vale da Universidade Federal do Rio Grande do Sul (UFRGS) para demonstrar a aplicação das equações e curvas desenvolvidas. As equações adimensionais foram úteis para determinar qual vazão nominal deveria ser adotada para que o sistema fosse mais eficiente hidroenergeticamente e, também, para determinar quanto de energia seria consumida a mais caso o ponto de funcionamento da bomba fosse alterado por válvula de estrangulamento.

Palavras-chave: Bombas centrífugas; Eficiência energética; Rendimentos máximos; Curvas adimensionais. 


\section{INTRODUCTION}

Water and energy are two of the most important resources used in various productive sectors and in the daily lives of populations. Energy consumption in the world is expected to increase by 30\% between 2016 and 2030 (EIA, 2016). Electric motors are responsible for the consumption of $46 \%$ of all energy consumed and, within this percentage, pumping systems account for $20 \%$ of consumption (EUROPEAN COMISSION, 2001).

The total financial expenditure per year in electricity in sanitation in Brazil is in the order of 5 billion reais, corresponding to the consumption of electric energy of $11 \mathrm{TWh}$. This amount is equivalent to the annual domestic consumption of about 19 million inhabitants (BRASIL, 2017). The magnitude of this consumption is quite significant, so that studies on the use of centrifugal pumps in water supply systems (WSS) are important in the economicenergy scenario, since approximately $90 \%$ of the electric energy in sanitation is consumed by motor-pump sets (GOMES, 2009).

The choice of pump type is usually done from the knowledge of the pumping discharge $(\mathrm{Q})$ and the head $(\mathrm{H})$ of the system, however, the field of application of the different types of pumps is wide and subject to overlapping regions which may cause a greater difficulty in this choice. Macintyre (2013) explains that the choice of pump can be made using graphs presented by the manufacturers in which, knowing the values of $\mathrm{Q}$ and $\mathrm{H}$, the type of pump suitable can be indicated. Other information presented in the manufacturer's curves are the yield, the ratio between the energy supplied to the duty fluid (net power) and the energy supplied to the axis of its rotor (motor power) (GOMES, 2009).

The yield of the motor-pump set is directly related to the energy consumption of the pumping system, therefore, during design, machines with high yield must be chosen and, during operation, the point of operation (intersection between the curve of the pump and the curve of the system) coincides with the point of maximum yield (PMY) indicated by the manufacturer or is close to it.

It is common to find water supply systems with oversized motor-pump sets. At the same time, the pumps can also become undersized with the growth in demand. In these cases, the vibrations and losses inside the pump increase and the working life of the equipment decreases (KOOR et al., 2016).

The maximum yield during the design of a pumping system needs to done carefully, since Macintyre (2013) points out that, for small centrifugal pumps, the yield can be less than $40 \%$ and, in large pumps, it can exceed $85 \%$, so that is to say that the energy consumption can vary significantly according to the chosen pump.

Santos (2007) further adds that the yield is affected by the geometry of the pump, which, in turn, is determined to meet the user's varied demands of $\mathrm{Q}$ and $\mathrm{H}$. That is, in some cases, the best possible yield can have low values, which does not mean that the pump is of poor quality, but only that the imposed work situation means greater losses of energy. Supporting this explanation, Gomes (2009) argues that the selection of a pump involves, besides the knowledge of the discharge and the head, the selection of the best size and shape (centrifugal, mixed or axial) of the pump.

In this sense, there are numerous pumps that can be chosen to meet the daily demand conditions of a water supply system, depending on the combination of the pumping discharge and the head. The efficient and effective choice, however, will be the one that uses the least amount of energy and financial resources and that effectively meets the demand. Arun Shankar et al. (2016) state that, considering the large energy consumption associated with pumping systems, all the actions directed to the investigations in this sense are valid.

Thus, the methodology described in this paper brings a dimensionless analysis of the characteristics of centrifugal pumps through information obtained in the curves available in the catalogs of several manufacturers that operate in the Brazilian market. Correlations are presented for estimating yields according to the nominal head $\left(\mathrm{H}_{1 / 1}\right)$ and the nominal pumping discharge $\left(\mathrm{Q}_{1 / 1}\right)$, aiming at a better understanding of the application, performance and preliminary estimates of the characteristics of the centrifugal pump to be adopted. The dimensionless analysis carried out had the objective of obtaining information that could be extrapolated to situations different from those studied in the research.

\section{PUMP SIMILARITY AND DIMENSIONLESS QUANTITIES}

The fluid machinery is similar in three spheres in three spheres: geometric, kinematic and dynamic. The geometrical similarity implies in the proportionality of the linear dimensions, the kinematic similarity implies that the vectors of velocity and acceleration, for corresponding points, are parallel and have a constant relation of their modules and, finally, the dynamic similarity is obtained when the identical types of forces acting on the system, for corresponding points, are parallel vectors and have a constant relation between their modules (HENN, 2012). To ensure that similarity criteria are met, a dimensional analysis must be performed. For the flow in hydraulic machines, the following functional relations can be considered, expressed by Equations 1 and 2:

$$
g H=f_{l}(Q, D, N, \rho, \mu, \varepsilon)
$$

$P=f_{2}(Q, D, N, \rho, \mu, \varepsilon)$

where: $\mathrm{g}$ is the gravitational acceleration, $\mathrm{H}$ is the head, Q is the discharge, $\mathrm{D}$ is the rotor diameter, $\mathrm{N}$ is rotor rotation, $\mathrm{Q}$ is the specific mass of the fluid, $\mu$ is the dynamic viscosity of the fluid, and $\varepsilon$ is the absolute surface roughness.

Applying the principles of dimensional analysis, for Equations 1 and 2, four dimensionless pi groups can be formed:

$$
\begin{aligned}
& \frac{g H}{n^{2} D^{2}}=g_{I}\left(\frac{Q}{n D^{3}}, \frac{\rho n D^{2}}{\mu}, \frac{\varepsilon}{D}\right) \\
& \frac{P}{\rho n^{3} D^{5}}=g_{2}\left(\frac{Q}{n D^{3}}, \frac{\rho n D^{2}}{\mu}, \frac{\varepsilon}{D}\right)
\end{aligned}
$$

The dimensionless quantities found in this analysis are important parameters for the flow in pumps. Table 1 presents the names of these dimensionless groupings.

Based on the dimensional analysis, it is said that two machines will be dynamically similar when there is equality between Reynolds, Mach, Froude, Weber and Euler numbers of each (HENN, 2012). 
Table 1. Dimensionless relations in pumps.

\begin{tabular}{cc}
\hline Reynolds number & $\operatorname{Re}=\frac{\rho \cdot n \cdot D^{2}}{\mu}$ \\
Manometric Coefficient & $=\frac{g \cdot H}{n^{2} \cdot D^{2}}$ \\
Discharge Coefficient & $\varphi=\frac{Q}{n \cdot D^{3}}$ \\
Power Coefficient & $\chi=\frac{P}{\rho \cdot n^{3} \cdot D^{5}}$ \\
Relative Roughness & $\xi=\frac{\varepsilon}{D}$ \\
\hline
\end{tabular}

Source: Santos (2007).

From the dimensionless parameters presented, Santos obtained Equation 5, which shows the yield of the pump $(\eta)$, a dimensionless quantity, determined by a relation involving other dimensionless parameters.

$\eta=\frac{\psi \cdot \varphi}{\chi}$

From these dimensionless parameters, it is possible to obtain the pump characteristic curves ( $\mathrm{xxQ}, \mathrm{PxQ}$ and $\eta x \mathrm{Q})$ as demonstrated by Freitas, Michels and Passos (2015). Another possibility from the study of dimensionless numbers is the similarity laws applied to hydraulic machines, which can be used to evaluate the performance of the same machine when the rotor diameters or rotations are modified.

\section{SPECIFIC ROTATION VELOCITY AND CENTRIFUGAL PUMP PERFORMANCE}

The specific rotation velocity (Ns) is a number obtained by the similarity laws that remain constant for similar pumps. Henn (2012) describes it as the shape coefficient of the rotor and defines it as the rotation velocity of a pump geometrically similar to that considered, sized for $\mathrm{H}=1 \mathrm{~m}$ and $\mathrm{Q}=1 \mathrm{~m}^{3} / \mathrm{s}$. Equation 6 is used to obtain $\mathrm{Ns}$ and their relation to the specific rotation velocity of Addison (nqA) is nqA $=3 \mathrm{Ns}$.

$N s=\frac{N \cdot \sqrt{Q_{1 / 1}}}{H_{1 / 1}^{3 / 4}}$

where $\mathrm{Ns}$ is the specific rotation velocity, $\mathrm{N}$ is the axis rotation (rpm), $Q_{1 / 1}$ represents the nominal discharge in $\mathrm{m}^{3} / \mathrm{s}$ and $\mathrm{H}_{1 / 1}$ is the nominal head of the pump (m).

Henn (2012) indicates that the specific rotation velocity is associated with the shape and proportions of fluid machinery rotors and their value, as well as serving as the basis for characterizing series of geometrically similar machines in manufacturer catalogs, is a fundamental element to select the type of machine most suitable for each situation. Santos (2007) reiterates that, although it belongs to a fictitious pump, the specific rotation velocity can be considered as a kind of property of real pumps and can be used to verify the importance of each quantity involved.

The different pump geometries were classified using the specific rotation velocity as shown in Table 2.
Table 2. Classification of pumps by specific rotation velocity.

\begin{tabular}{cl}
\hline Ns (rpm) & \multicolumn{1}{c}{ Type of Pump } \\
\hline$<10$ & Positive displacement - gears, vane, pistons, etc. \\
10 to 40 & Radial Centrifugal \\
35 to 85 & Helical Centrifugal \\
80 to 150 & Diagonal Centrifugal \\
125 to 500 & Axial \\
\hline \multicolumn{2}{l}{ Source: Santos (2007). }
\end{tabular}

Figure 1 shows the different types and yields of pumps depending on the discharge and the specific rotation velocity, and similarly, Figure 2 presents an estimate of the type and yield of the pump as a function of the specific rotation velocity. It should be noted, however, that the adjustment equations of these curves are not presented, which may complicate the estimation of the yield in preliminary stages of the design. Both graphs of Figures 1 and 2 show a tendency to increase yield by increasing the specific rotation velocity of centrifugal pumps up to a given value of nqA or Ns. The yield information, depending on the specific rotation velocity, can aid in the choice of the design discharge of the supply systems, since the energy consumed in pumping is a function of the pumping discharge, head and yield of the pump.

Several researchers have been studying the yield of centrifugal pumps. Alé (2010) proposes an estimation of the order of magnitude of the overall yield of pumps as a function of the discharge and the head and presents Equation 7, valid for pumping discharges between 20 and $250 \mathrm{~m}^{3} / \mathrm{h}$ and heads between 15 and $100 \mathrm{~m}$.

$\eta=a-b H+c Q H-d Q^{2} H+e H^{2}-f Q H^{2}+g Q^{2 H^{2}}$

where:

$a=80 ; b=0.9367 ; c=5.46 \times 10^{-3} ; d=1.514 \times 10^{-5} ; e=5.802 \times 10^{-3} ;$

$f=-3.028 \times 10^{-5} ; g=8.346 \times 10^{-8} ; \eta$ is the overall yield of the centrifugal pump; Q, the discharge $\left(\mathrm{m}^{3} / \mathrm{h}\right)$ and $\mathrm{H}$, the head $(\mathrm{m})$.

Coelho and Andrade-Campos (2016) developed a methodology to estimate the yield behavior of a pump operated with a frequency converter. The authors stated that, although frequency converters are widely used, there are few studies on the effect of the rotation variation on pump yield and have proposed an equation to obtain the yield when the rotation is modified.

Koor, Vassiljev and Koppel (2016) studied the yield of lift stations with non-identical pumps working in parallel and with rotational variation. The authors reinforced the importance of the research because, in many practical cases, initially the pumps are identical, however, with the excessive use of one to the detriment of another, the resulting wear and tear modifies the yield of the pump and, therefore, the overall lift yield.

In addition to the yield of the pump, it is necessary to evaluate the yield of the motor. Electric motors are used to drive the pump shaft, converting electric energy into electromagnetic energy and this, in turn, into mechanical energy on its axis. In each energy transformation, losses occur, determining its yield.

Electric motors are manufactured to operate at maximum constant yield ranging between $75 \%$ and $100 \%$ of their nominal load. Operation with load higher than nominal should be avoided (WEG, 2016). 
Thus, motors with higher power than the one supplied to the pump are selected to operate in the maximum yield range, avoiding overload.

\section{METHODOLOGY}

From the centrifugal pump curves found in catalogs of four different manufacturers, widely used in Brazil, the discharge and head data were collected at the point of maximum yield.

The centrifugal pumps of manufacturer A, B and D are of horizontal axis, single stage, single suction horizontal with closed radial rotor. The pumps of line 1 and 2, of manufacturer $C$, have an open and semi-open rotor, respectively. All are suitable for pumping water and clean, turbid liquids. The analyzed pump quantities of each manufacturer and line are shown in Table 3, and their characteristics are presented in Table 4.

The specific rotation velocity $(\mathrm{Ns})$ was calculated by Equation 6 in the PMY and was correlated to the maximum yield for each of the pumps analyzed.

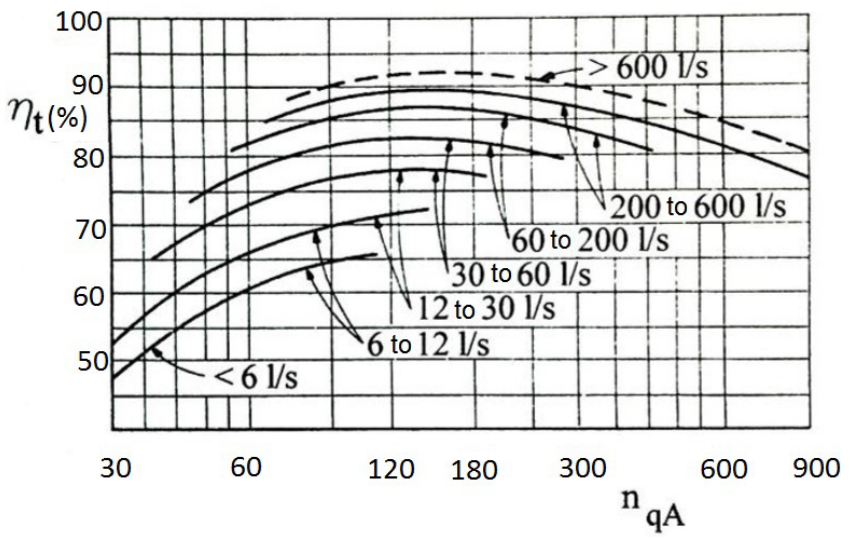

Figure 1. Yield according to the specific rotation velocity by ranges of discharge (Bureau of Reclamation, 1976 apud HENN, 2012, p. 120).
From the calculation of the specific rotation velocity, curves were constructed to relate this information to the yield at that point. The objective of this analysis was to try to provide an estimate of the expected maximum yield for different operating conditions and to verify if there was a good fit between this information, making it possible to establish equations that can be used to estimate the yield in different design situations.

For the pumps of the manufacturers A (line 1) and B, more curve data were collected, namely: head at the shutoff point, head, discharge and yield at four other points of the curve, two to the left and two to the right of the curve's PMY, so that it was possible to represent the entire region of pump operation

Table 3. Centrifugal pumps analyzed in the research.

\begin{tabular}{ccc}
\hline Fabricant & Quantity & Rotor \\
\hline A - line1 & 107 & Closed \\
A - line2 & 139 & Closed \\
A - line3 & 131 & Closed \\
B - line1 & 56 & Closed \\
C - line1 & 24 & Open \\
C - line2 & 27 & Semi-open \\
D - line1 & 54 & Closed \\
TOTAL & $\mathbf{5 3 8}$ & \\
\hline
\end{tabular}

Table 4. Characteristics of the centrifugal pumps analyzed in the research.

\begin{tabular}{ccccc}
\hline Manufacturer & $\begin{array}{c}\mathbf{Q m i n} \\
\left(\mathbf{m}^{3} \mathbf{h}\right)\end{array}$ & $\begin{array}{c}\text { Qmáx } \\
\left(\mathbf{m}^{3} \mathbf{h}\right)\end{array}$ & $\begin{array}{c}\text { Hmin } \\
(\mathbf{m})\end{array}$ & $\begin{array}{c}\text { Hmáx } \\
(\mathbf{m})\end{array}$ \\
\hline A - line1 & 5.9 & 1090 & 3.4 & 115 \\
A - line2 & 2.75 & 1660 & 3.1 & 130 \\
A - line3 & 2.74 & 1120 & 3.1 & 210 \\
B - line1 & 10.3 & 1035 & 5.5 & 210 \\
C - line1 & 87.0 & 2450 & 12.1 & 92 \\
C - line2 & 13.5 & 195 & 8.51 & 162 \\
D - line1 & 9.7 & 73 & 11.0 & 80 \\
\hline
\end{tabular}

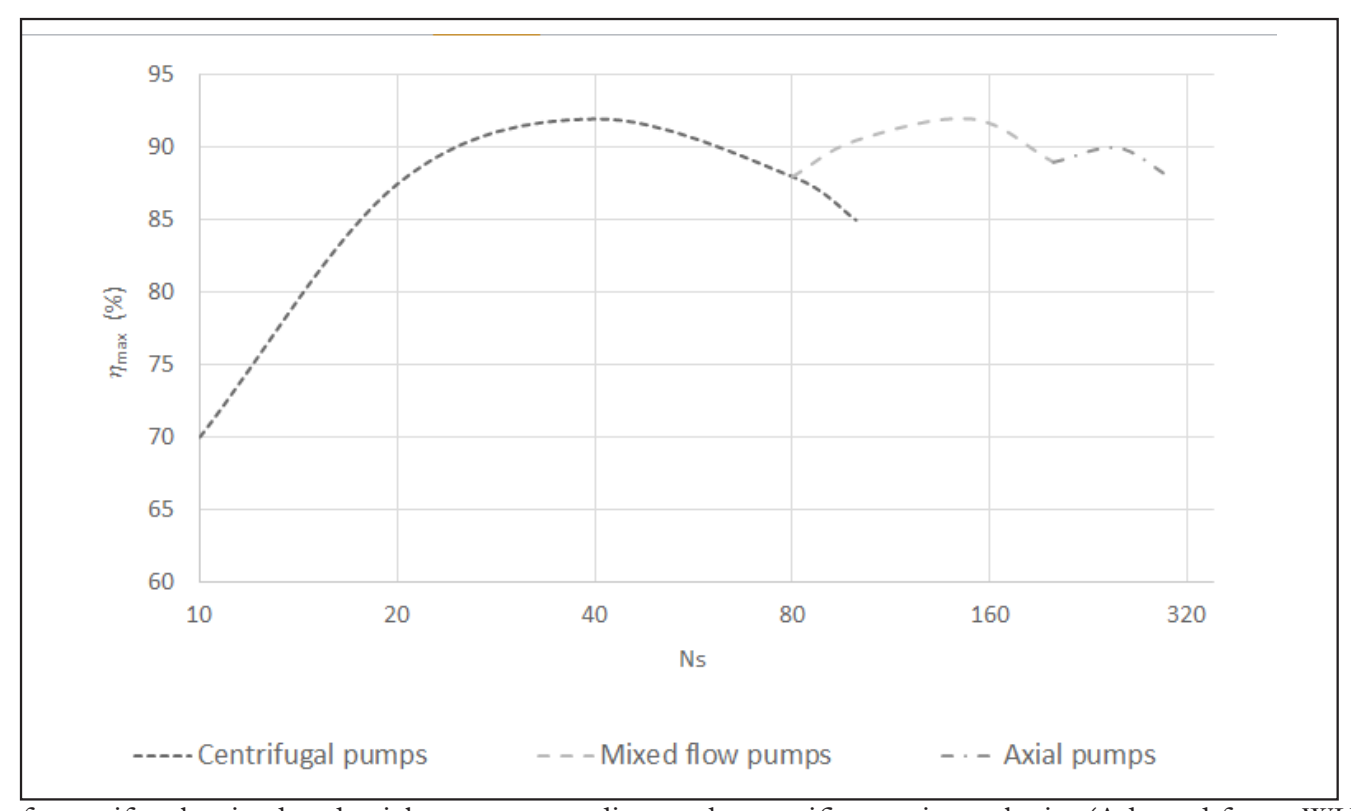

Figure 2. Yield of centrifugal, mixed and axial pumps according to the specific rotation velocity (Adapted from: WHITE, 2002). 
Therefore, for each pump, the PMY $\left(\mathrm{H}_{1 / 1}, \mathrm{Q}_{1 / 1}\right.$ e $\left.\eta_{\text {max }}\right)$ and other four points $(\mathrm{H}, \mathrm{Q}$ and $\eta$ ) along the curve were obtained.

For each pump, the values collected (H, Q and $\eta)$ were divided (made dimensionless) by the values of the respective PMY. Thus, it was possible to adjust a single dimensionless curve to represent the analyzed pumps and verify the variation of the parameters of the centrifugal pump in relation to the point of maximum yield.

The dimensionless yield $\left(\eta / \eta_{\max }\right)$ has a maximum value of 1 in the PMY (where $\mathrm{H}=\mathrm{H}_{1 / 1}$ and $\mathrm{Q}=\mathrm{Q}_{1 / 1}$ ), and lower values for other combinations of $\mathrm{H} / \mathrm{H}_{1 / 1}$ and $\mathrm{Q} / \mathrm{Q}_{1 / 1}$ analyzed.

For the estimation of motor yield, a procedure analogous to that used to determine the yield of the pumps was carried out. Yield data were collected from three-phase electric motors from three manufacturers recognized in the Brazilian market available in INMETRO (2002) tables and, from these data, an equation was adjusted that allowed obtaining the yield of the motor from the electric power. The motors analyzed were three-phase, 2-pole, with power between $0.75 \mathrm{~kW}$ and $185 \mathrm{~kW}$, with yields between $77 \%$ and $94.3 \%$.

\section{RESULTS}

Figure 3 presents the yield data as a function of the specific rotation velocity for all analyzed pumps. It can be observed that there is a tendency to increase the maximum yield $\left(\eta_{\max }\right)$ with the increase of the specific rotation velocity of centrifugal pumps. For low specific velocitys (less than 30), pump yields range from $20 \%$ to $80 \%$. For Ns between 40 and 120 , yields remained more stable with values close to $80 \%$.

From the data presented in Figure 3, a curve fitting equation (Equation 8) was determined, with coefficient of determination of 0.8782 , according to the adjustment line shown in the figure.

$\eta_{\text {máx }}(\%)=e^{5.092-\frac{9.121}{N s}-0.124 \ln (N s)}$ where $\eta_{\max }$ is the maximum yield of the centrifugal pump (\%) and Ns, the specific rotation velocity.

The yield curve as a function of the specific rotation velocity matches the curves found in the literature (HENN, 2012; WHITE, 2002; ALÉ, 2010), and the maximum yield occurs near 40 Ns (120 Nqa). In order to include the equation presented by Alé (2010), the yield is presented as a function of the specific rotation velocity for three values of head. Figure 4 compares the adjusted curve in this paper with data from the literature. It should be noted that the curves presented by USBR (1976 apud HENN, 2012, p. 120), are for different discharge ranges, as shown in Figure 1.

In small water supply systems, it may be interesting to analyze the choice of pumps with a specific rotation velocity around $40 \mathrm{Ns}$, since their yield will be higher. To increase Ns, it is necessary to increase the pumping discharge or decrease the head. In case of increase in discharge, the pump power will also be higher, which leads to greater energy and financial expenditure. On the other hand, increasing the pumping discharge can mean reducing the operating time of the pumping system, that is, reducing the energy and financial consumption. In view of this, hydropower efficiency evaluations of pumping systems are complex and need to be performed more broadly than mere considerations of the motor-pump set yield. In this sense, studies are necessary that take into account several criteria to verify if the change of $\mathrm{Ns}(\mathrm{H}$ or Q $)$ represents an advantage when it comes to energy.

Figure 5 and Figure 6 graphically present the $\mathrm{HxQ}$ and $\eta \times \mathrm{Q}$ curves made dimensionless by means of the methodology proposed in this research.

These results are derived from the analysis of the pumps of manufacturer A, line 1 and of manufacturer B. It was possible to observe that the centrifugal pumps have a mean maximum head around 1.25 times the corresponding nominal head, which corroborates the above in Macintyre (2013).

The equation of adjustment (9) was obtained from the data of Figure 5 and is a quadratic function whose coefficient of determination is of 0.9402 , with an accuracy of $\pm 2 \%$.

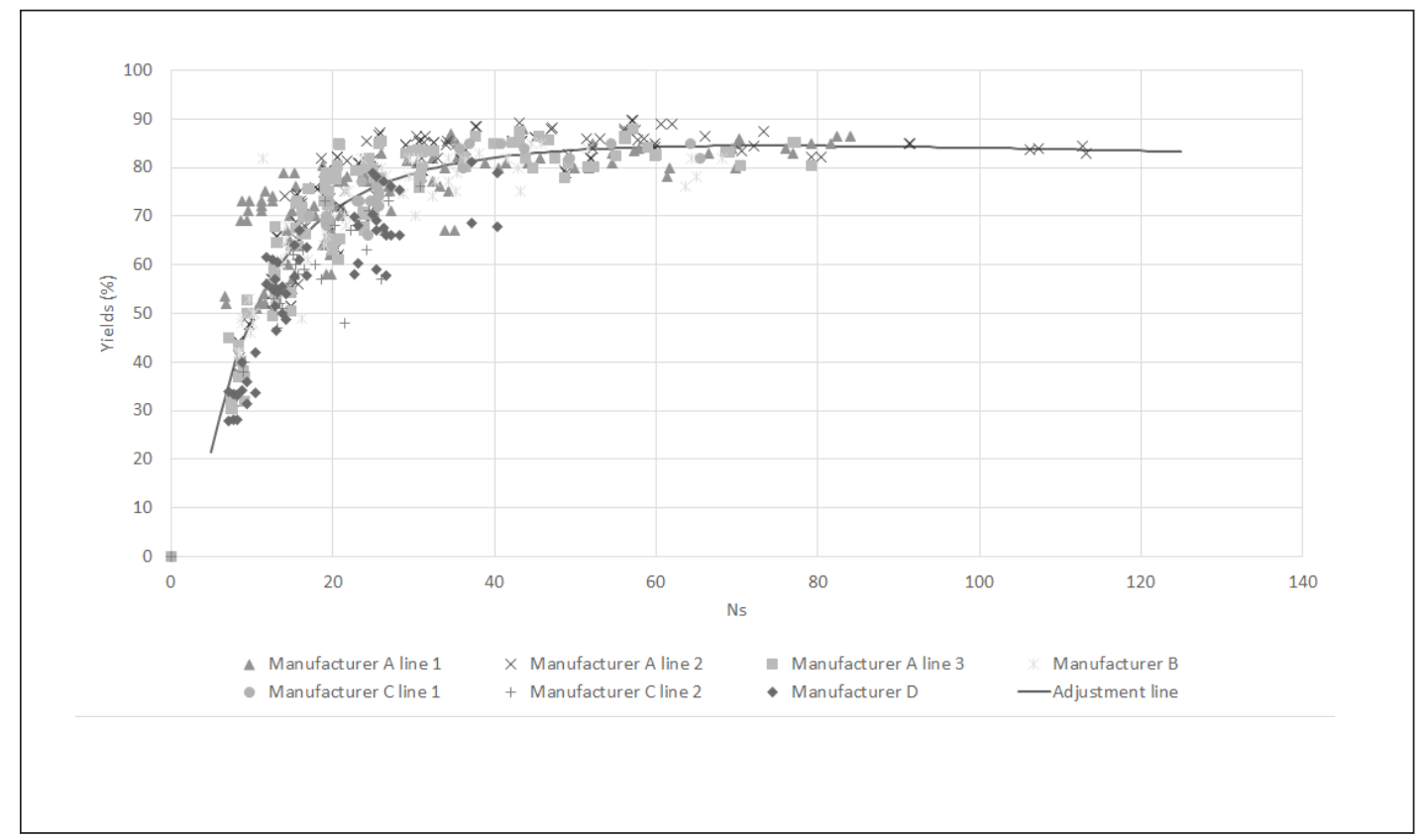

Figure 3. Yields of the centrifugal pumps analyzed in the research as a function of Ns. 
$\frac{H}{H_{1 / 1}}=1.245-0.265\left(\frac{Q}{Q_{1 / 1}}\right)^{2}$

where $\mathrm{H}$ is the head $(\mathrm{m}) ; H_{1 / 1}$, nominal head; $\mathrm{Q}$, the pumping discharge $\left(\mathrm{m}^{3} / \mathrm{s}\right)$ and $Q_{1 / 1}$, the nominal discharge $\left(\mathrm{m}^{3} / \mathrm{s}\right)$.

The analysis of the dimensionless yield (Figure 6) showed that this quantity also has a quadratic behavior with the discharge

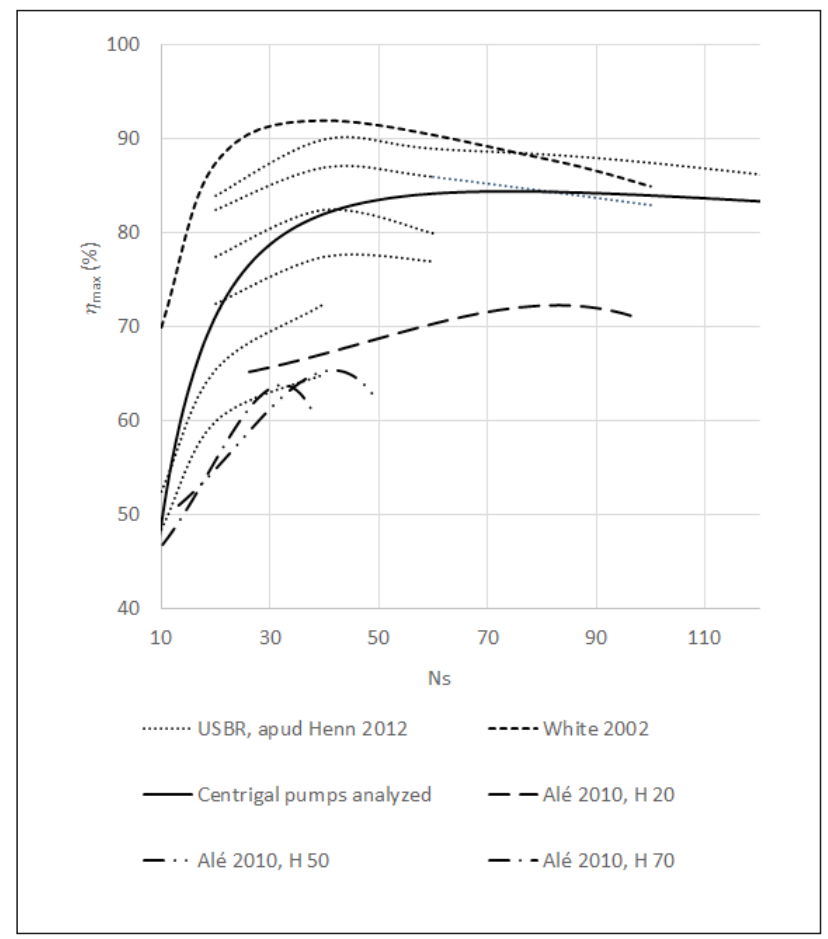

Figure 4. Comparison between the curve obtained in this research and others in the literature. variation. The yield decreases as the discharge is changed, for example, for discharge values between $60 \%$ and $140 \%$ of that of the PMY, the yield decreases up to $85 \%$ of the nominal yield, which can aid in estimating the yield when the pump's point of operation is altered.

The drop in yield will be even more significant when the discharge is altered to less than $60 \%$ or to more than $140 \%$ of the nominal discharge, decreasing to $40 \%$ of the nominal yield. Equation 10 represents the adjustment of the data of Figure 6, its coefficient of determination is 0.991 , with an accuracy of $\pm 1 \%$.

$\frac{\eta}{\eta_{\text {máx }}}=-0.995\left(\frac{Q}{Q_{\frac{1}{l}}}\right)^{2}+1.977 \frac{Q}{\frac{Q_{l}}{l}}+0.025$

where $\eta$ is the yield; $\eta_{\max }$, the maximum yield; $\mathrm{Q}$, the pumping discharge $\left(\mathrm{m}^{3} / \mathrm{s}\right)$ and $Q_{1 / 1}$, the nominal discharge $\left(\mathrm{m}^{3} / \mathrm{s}\right)$.

With the information in Figures 5 and 6 it was possible to draw up the dimensionless curve presented in Figure 7, which shows the head as a function of the discharge $(\mathrm{H}=\mathrm{f}(\mathrm{Q}))$ with the estimation of the yields along the pump's operating curve.

The yield of the 2-pole three-phase electric motors was correlated with their nominal power, generating the adjustment Equation 11 whose coefficient of determination is 0.9950 . Figure 8 shows the dispersion of the obtained data and the line of the adjustment equation.

$\eta m=\frac{21.97+97.64 P m^{0.4}}{0.53+P m^{0.4}}$

where $\eta m$ is the yield of the 2-pole three-phase motor (\%); Pm, the power of the motor $(\mathrm{kW})$.

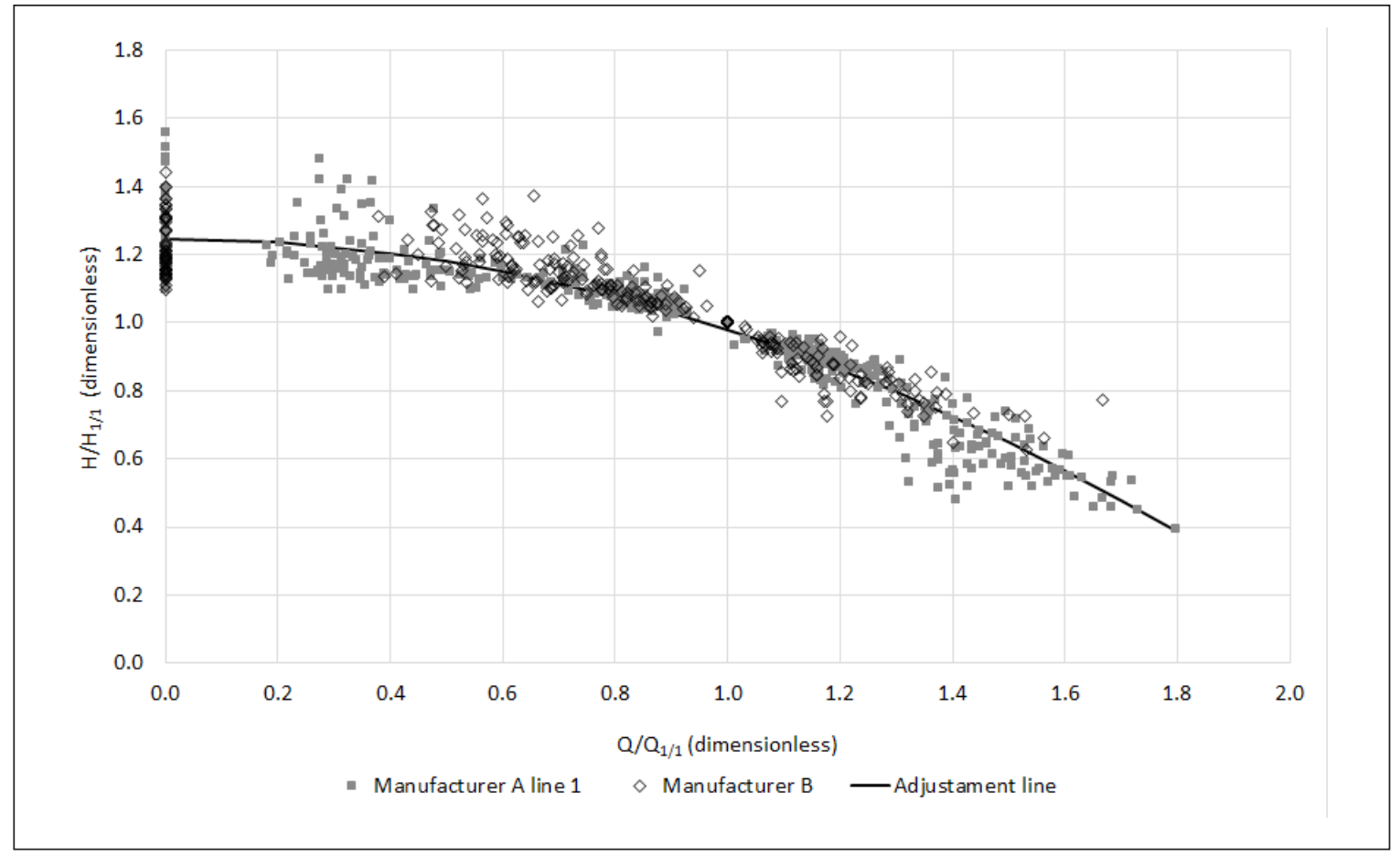

Figure 5. Dimensionless pump curve for various centrifugal pumps. 


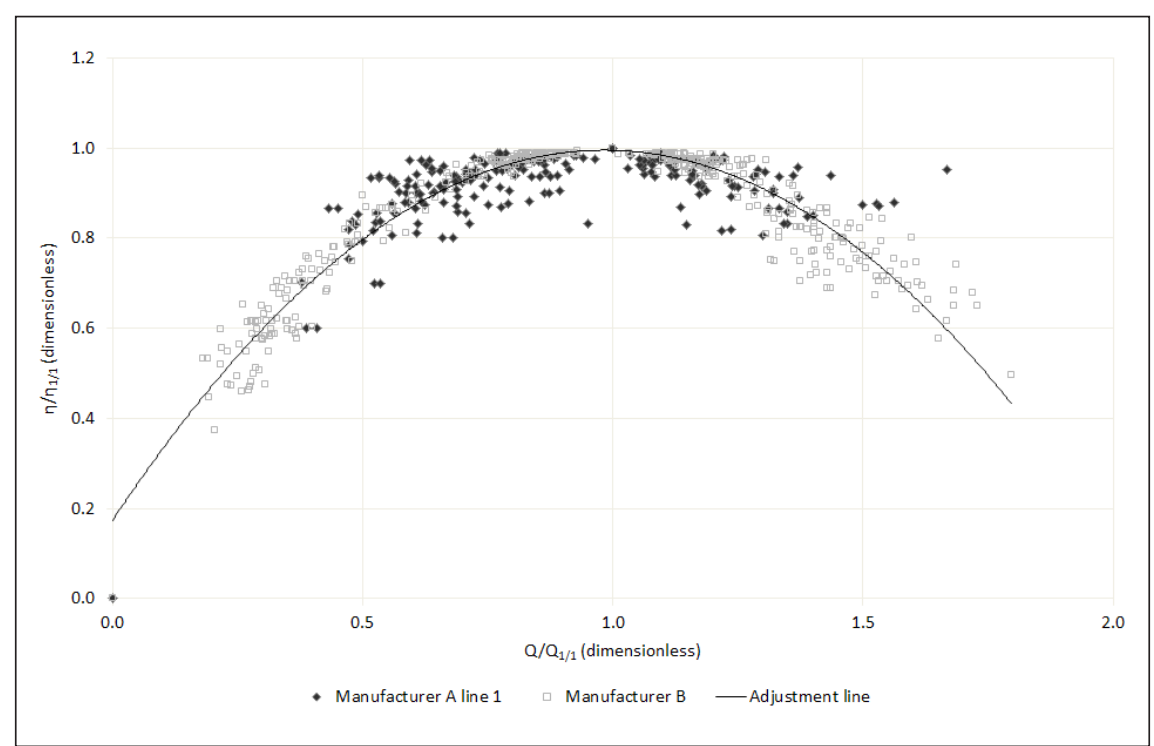

Figure 6. Yield as a function of the dimensionless discharge.

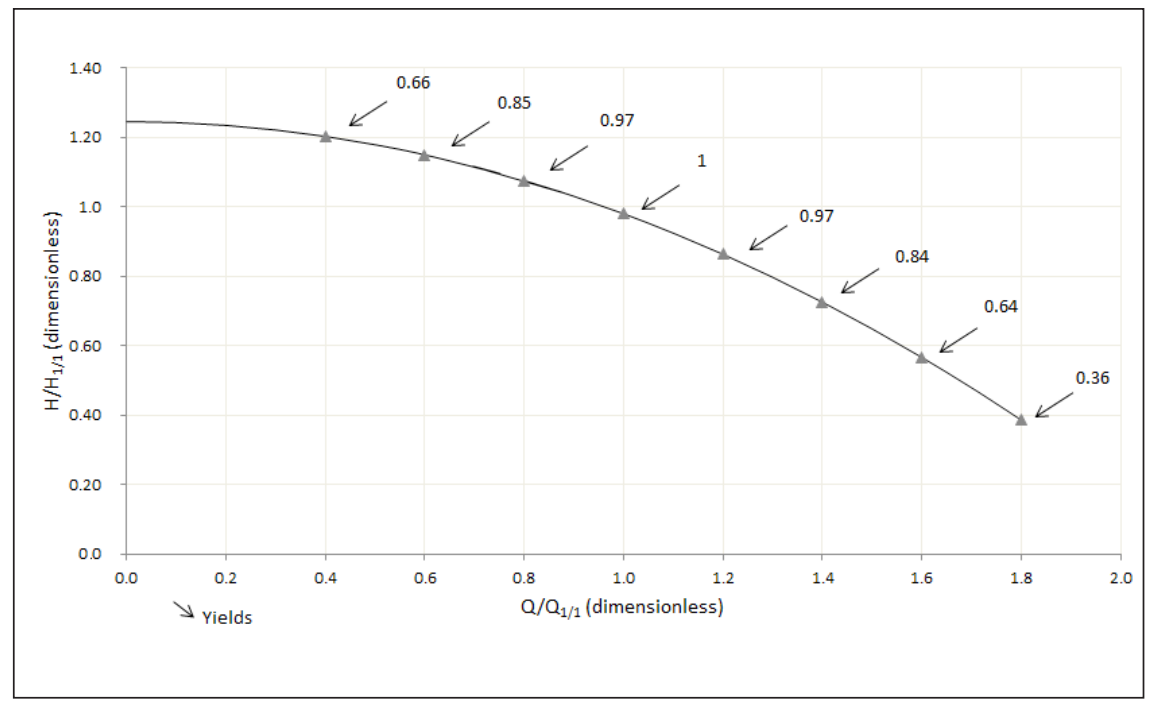

Figure 7. Dimensionless pump operating curve.

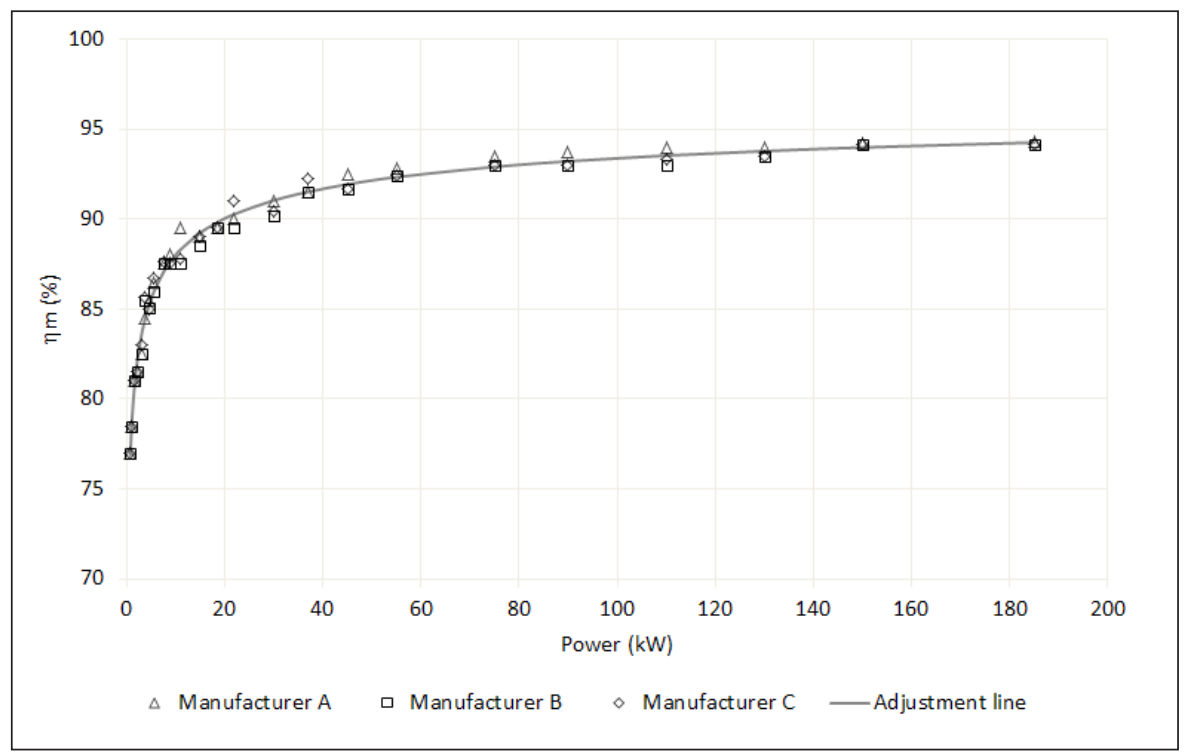

Figure 8. Yields for the 2-pole three-phase electric motors as a function of nominal power. 


\section{APPLICATION}

In order to demonstrate the application of the dimensionless curve of the pump (Figure 7), a case study was made for the optimal determination of the pumping capacity to be adopted. This case study is based on data from the Water Supply System of the Beltway of the Vale Campus of the Federal University of Rio Grande do Sul (UFRGS), measured in loco during the execution of the REDECOPE project - Development of Technologies and Efficient Procedures for The Hydroenergetic Management in Water Supply Systems, by the team of LENHS - Laboratory of Energy Efficiency and Hydraulics in Sanitation of UFRGS.

The application of curves, equations or models developed by researchers in case studies can be very useful to validate or exemplify the usage. Zocoler et al. (2011) adjusted a mathematical model to quantify the effect of the variation of hydraulic pump yield on the variation of the costs of a pumping system. In order to demonstrate the application and to validate the model, the authors proposed a case study in which they evaluated three centrifugal pumps with different costs of acquisition and yields and concluded that, although more expensive, pumps with higher yields were preferable to the detriment of the others, since the period to recover the investment was less than the working life of the equipment.

\section{System features}

The characteristics of the system are presented below:

- Mean daily consumption is $270 \mathrm{~m}^{3}$ / day, from Monday to Friday and $219 \mathrm{~m}^{3}$ / day from Monday to Sunday (Figure 9);

- Maximum hourly consumption is $27 \mathrm{~m}^{3} / \mathrm{h}$ on average;

- Geometric height is $67.8 \mathrm{~m}$;

- Consumption peaks are close to noon and at $3 \mathrm{pm}$;
- Mean hourly consumption is $11.5 \mathrm{~m}^{3} / \mathrm{h}$;

- Demand factor is 0.42 ;

- Total length of the settlement's cast iron pipe is $1062 \mathrm{~m}$, with more than 15 years of use;

- Internal diameter is $0.1458 \mathrm{~m}$;

- Absolute roughness is $2.5 \mathrm{~mm}$;

- Total k coefficient of singular head losses, estimated by Tonial (2014), equal to 597.99;

- Upper reservoir volume is $700 \mathrm{~m}^{3}$.

The water is delivered by the Municipal Department of Water and Sewage of Porto Alegre (DMAE), and is pumped by a single motor-pump set to the upper reservoir.

In the lift station, there are 4 motor-pump sets arranged in parallel, however, currently only 2 motor-pump sets are active, one of them being a backup set. The motors are of the WEG brand, JP-Plus model, with $75 \mathrm{HP}$ of power and the pumps are centrifugal, monostage, monoblock, series DN 65-25 Mark Grundfus of $3500 \mathrm{rpm}$, with nominal discharge of $112.5 \mathrm{~m}^{3} / \mathrm{h}$, nominal head of $115 \mathrm{~m}$ and yield $69.3 \%$.

\section{System head}

The pump's yield and head estimates can be calculated using Equations 9 and 10. In order to use them it is necessary to calculate the head of the system and choose the pumping discharges for the operation of the system, always striving to meet the consumption requirements and for the good use of the reservoir.

The head corresponds to the sum of the geometric height with the system head losses. Continuous head loss can be calculated using the Darcy-Weisbach Formula 12 and the singular head loss with the Borda-Carnot Formula 14.

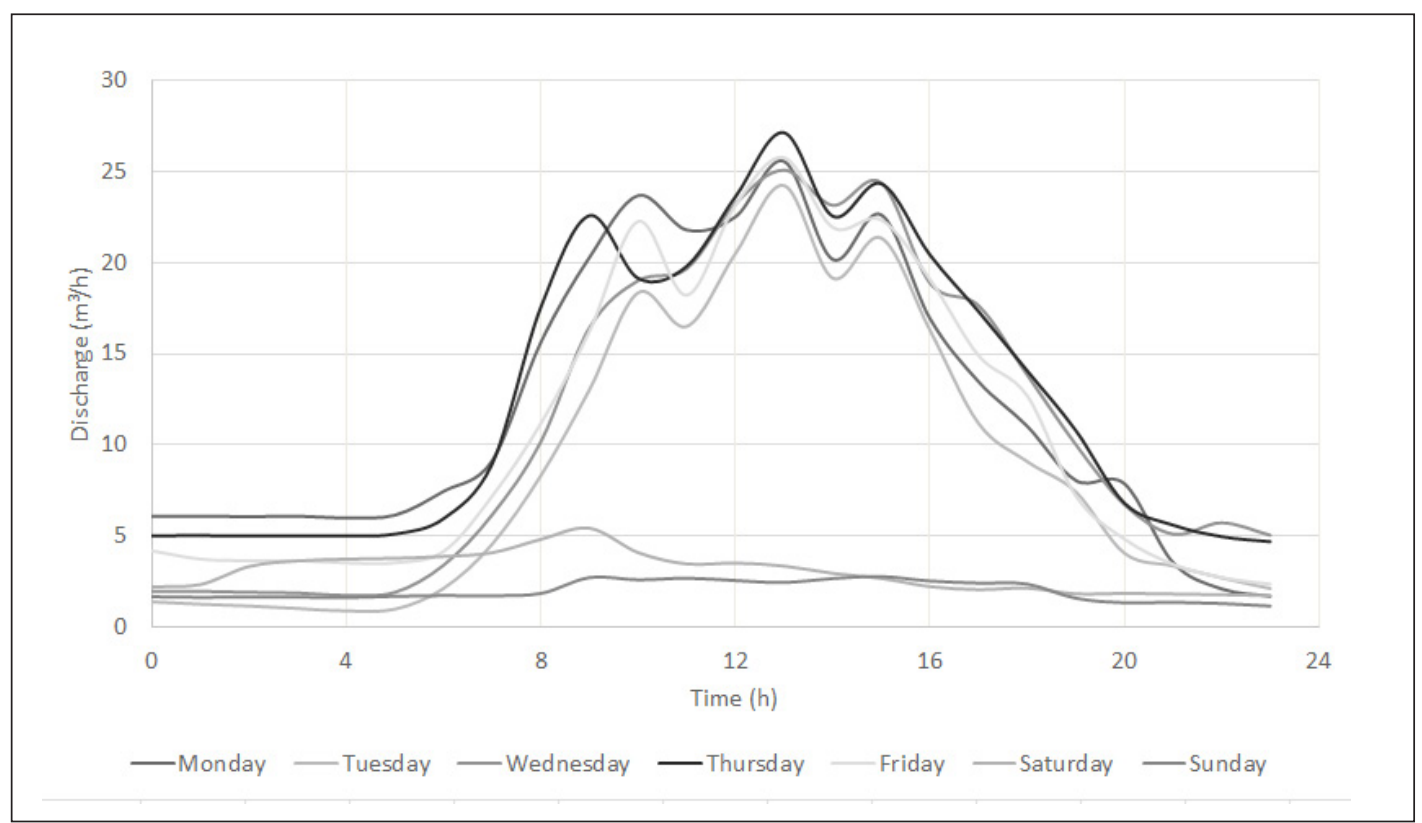

Figure 9. Hourly consumption of the Water Supply System of the Beltway of the Vale Campus of UFRGS. 
$H l=f \frac{L}{D} \frac{V^{2}}{2 g}$

where $\mathrm{Hl}$ is the continuous head loss ( $\mathrm{m})$; $\mathrm{F}$, the friction coefficient; $\mathrm{L}$, the length of the pipe $(\mathrm{m}) ; \mathrm{V}$, the mean flow velocity in the pipe $(\mathrm{m} / \mathrm{s}) ; \mathrm{D}$, the internal diameter of the pipeline $(\mathrm{m})$ and $\mathrm{g}$, the acceleration of gravity $\left(\mathrm{m} / \mathrm{s}^{2}\right)$.

The friction coefficient of Equation 12 can be calculated with the Colebrook-W Wite equation:

$$
\frac{1}{\sqrt{f}}=-2 \log \left(\frac{\varepsilon / d}{3.7}+\frac{2.51}{\operatorname{Re} \sqrt{f}}\right)
$$

where $\varepsilon$ is the absolute roughness $(\mathrm{mm})$; $\mathrm{D}$, the pipe inner diameter ( $\mathrm{mm})$ and Re, the Reynolds number.

$$
H s=k \frac{V^{2}}{2 g}
$$

where $\mathrm{Hs}$ is the singular head loss (m) and $\mathrm{k}$, the head loss coefficient of each singularity.

\section{System power consumption}

The energy consumed can be calculated using Equation 15 , which corresponds to the hydraulic power, considering the yield of the centrifugal pump and the motor, multiplied by the pumping time.

$E=\frac{\gamma Q H}{1000 b m} t$

where $\mathrm{E}$ is the energy consumed by the centrifugal pump ( $\mathrm{kWh}$ ); $\gamma$, the unit weight of water $\left(\mathrm{N} / \mathrm{m}^{3}\right)$; $\mathrm{Q}$, the pumping discharge $\left(\mathrm{m}^{3} / \mathrm{s}\right) ; \mathrm{H}$, the head $(\mathrm{m}) ; \eta \mathrm{b}$, the yield of the pump; $\eta \mathrm{m}$, the yield of the motor and $t$, the pumping time $(h)$.

\section{Operating considerations}

Five pumping rates were utilized, the first corresponding to the maximum hourly consumption discharge, $30.0 \mathrm{~m}^{3} / \mathrm{h}$, the second corresponding to twice the maximum hourly discharge, $60.0 \mathrm{~m}^{3} / \mathrm{h}$ and the third corresponding to the mean daily discharge demand, adopted as $12.5 \mathrm{~m}^{3} / \mathrm{h}$. Also, intermediate discharges of $20 \mathrm{~m}^{3} / \mathrm{h}$ and $40 \mathrm{~m}^{3} / \mathrm{h}$ were utilized. The point of operation for the centrifugal pump for the analysis was at the point of maximum yield.

The mode of operation of the reservoir of this WSS is with the use of a float switch. Although the reservoir has a capacity of $700 \mathrm{~m}^{3}$, the active storage adopted was $300 \mathrm{~m}^{3}$ for the maximum and minimum elevations for the motor's activation with the use of the float switch, since in order to maintain water quality, it is recommended that the stored volume is not higher than the daily consumption volume.

The determination of the total pumping time and of the time on peak hours was done from a mass balance of the reservoir volume, volume consumed and volume pumped, with intervals of time in minutes, totaling 4 weeks of consumption of hourly consumption curves of the Figure 9, with operation by means of float switch, according to Equations 16 and 17.

$\operatorname{Vr}(t)=\operatorname{Vr}(t-1)-C(t-1)$

$\operatorname{Vr}(t)=\operatorname{Vr}(t-1)-C(t-1)+B(t-1)$

where $\operatorname{Vr}(t)$ is the volume of the reservoir at time $t ; \operatorname{Vr}(t-1)$, the volume of the reservoir at time $\mathrm{t}-1 ; \mathrm{C}(\mathrm{t}-1)$, the volume consumed at time $\mathrm{t}-1 ; \mathrm{B}(\mathrm{t}-1)$, the volume pumped at time $\mathrm{t}-1$.

\section{Financial cost}

The energy cost, calculated by Equation 18, is relative to the supply class A4 of CEEE (2016), with modality of green hourly tariff, and values of November 2016 for tariff and taxes.

$R \$=\frac{P \cdot\left(\frac{R \$}{k W}+\frac{R \$}{k W h p} t p+\frac{R \$}{k W f p} t f p\right)}{1-(I C M S+P I S+C O F I N S)}$

where $\mathrm{P}(\mathrm{kW})$ is the electric power (Equation 19); $\frac{R \$}{k W p}$, the demand rate; $\frac{R \$}{k W h p}$ the energy tariff at the peak; $\frac{R \$}{k W h f p}$, the energy tariff outside the peak; Tp, peak pumping time; Tfp, pumping time off the peak and ICMS, PIS and COFINS taxes.

$$
P=\frac{\gamma Q H}{1000 b m}
$$

\section{RESULTS}

The results of the estimation carried out for the previously described case study are presented in Table 5. Figure 10 expresses the relation between the energy consumed and the yield of the motor-pump set for each of the evaluated dischargess. It is observed that the lowest energy consumption occurred for the discharge of $20 \mathrm{~m}^{3} / \mathrm{h}, 2633.86 \mathrm{kWh}$, but was very similar to the consumption for the discharge of $30 \mathrm{~m}^{3} / \mathrm{h}, 2637.72$. The minimum cost also occurred for these discharges and presented a value of $\mathrm{R} \$ 1610.89$ and $R \$ 1689.46$ for discharges of $20 \mathrm{~m}^{3} / \mathrm{h}$ and $30 \mathrm{~m}^{3} / \mathrm{h}$, respectively. The discharge of $30 \mathrm{~m}^{3} / \mathrm{h}$ can be indicated as the best choice in this case, since it provides greater reliability to the demand, in detriment of the flow of $20 \mathrm{~m}^{3} / \mathrm{h}$, with practically the same cost.

The indicators cost per cubic meter $\left(\mathrm{R} \$ / \mathrm{m}^{3}\right)$, energy consumption per cubic meter $\left(\mathrm{KWh} / \mathrm{m}^{3}\right)$ and cost per energy $(\mathrm{R} \$ / \mathrm{kWh})$, presented in Table 5 , were not very sensitive to the flow variation and can lead to an erroneous analysis of hydropower efficiency when analyzed individually.

Among the evaluated discharges, the smallest of them $\left(12.5 \mathrm{~m}^{3} / \mathrm{h}\right)$ resulted in a lower power value, lower yield and longer operating time, which resulted in one of the highest values of energy consumption. The low yield and high pumping time were responsible for the high energy consumption. The intermediate discharges $\left(20 \mathrm{~m}^{3} / \mathrm{h}\right.$ and $\left.30 \mathrm{~m}^{3} / \mathrm{h}\right)$ were the ones that resulted in lower cost and energy consumption, both with close results.

The higher discharges $\left(40 \mathrm{~m}^{3} / \mathrm{h}\right.$ and $\left.60 \mathrm{~m}^{3} / \mathrm{h}\right)$, despite having a higher performance of the motor-pump set, resulted in 
Table 5. Preliminary estimates of the characteristics of centrifugal pumps for substitution.

\begin{tabular}{|c|c|c|c|c|c|}
\hline Discharge $\left(\mathrm{m}^{3} / \mathrm{h}\right)$ & 12.5 & 20 & 30 & 40 & 60 \\
\hline Velocity (m/s) & 0.21 & 0.33 & 0.50 & 0.67 & 1.00 \\
\hline Coefficient $\mathrm{f}$ & 0.0416 & 0.0410 & 0.0407 & 0.0405 & 0.0403 \\
\hline Reynolds & 30231.46 & 48370.34 & 72555.51 & 96740.68 & 145111.03 \\
\hline$\varepsilon(\mathrm{mm})$ & 1.70 & 1.70 & 1.70 & 1.70 & 1.70 \\
\hline Diameter (mm) & 145.80 & 145.80 & 145.80 & 145.80 & 145.80 \\
\hline Continuous head loss (m) & 0.67 & 1.69 & 3.76 & 6.66 & 14.92 \\
\hline Single head loss (m) & 1.32 & 3.37 & 7.59 & 13.50 & 30.37 \\
\hline Head (m) & 63.99 & 67.06 & 73.36 & 82.16 & 107.29 \\
\hline Ns & 9.12 & 11.13 & 12.75 & 13.52 & 13.55 \\
\hline$\eta_{1 / 1}(\%)$ & 45.49 & 53.19 & 58.02 & 60.00 & 60.09 \\
\hline Shaft power $(\mathrm{kW})$ & 4.79 & 6.87 & 10.34 & 14.92 & 29.19 \\
\hline Motor power (kW) & 5.50 & 9.00 & 15.00 & 18.50 & 37.00 \\
\hline$\eta m(\%)$ & 85.93 & 87.66 & 89.23 & 89.82 & 91.51 \\
\hline Electric power grid (kW) & 5.52 & 7.88 & 11.70 & 16.89 & 32.82 \\
\hline Operating time out of peak (h) & 490.42 & 293.28 & 197.66 & 153.26 & 102.17 \\
\hline Operating time at the peak $(\mathrm{h})$ & 60.00 & 40.92 & 27.69 & 21.00 & 18.00 \\
\hline Energy consumed (kWh) & 3037.21 & 2633.86 & 2637.72 & 2943.44 & 3943.59 \\
\hline Monthly cost (R\$/month) & 1730.73 & 1610.89 & 1689.46 & 1950.49 & 2973.88 \\
\hline$\eta$ motor-pump set (\%) & $39 \%$ & $47 \%$ & $52 \%$ & $54 \%$ & $55 \%$ \\
\hline $\mathrm{R} \$ / \mathrm{kWh}$ & 0.62 & 0.63 & 0.63 & 0.64 & 0.77 \\
\hline $\mathrm{R} \$ / \mathrm{m}^{3}$ & 0.27 & 0.25 & 0.24 & 0.26 & 0.41 \\
\hline $\mathrm{kWh} / \mathrm{m}^{3}$ & 0.45 & 0.39 & 0.39 & 0.42 & 0.53 \\
\hline
\end{tabular}

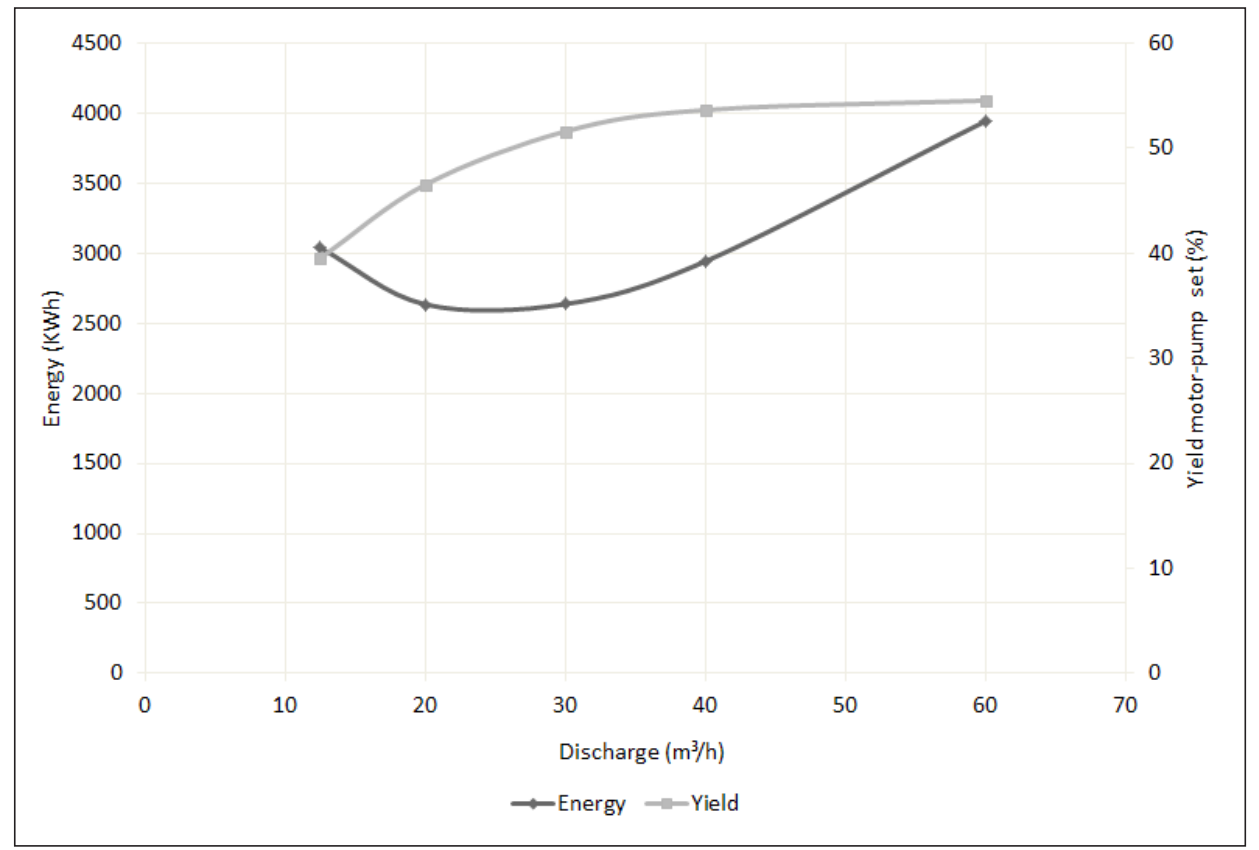

Figure 10. Energy consumption and overall yield of the motor-pump set for different service discharges for the Valley Campus of UFRGS.

the need to increase the installed power, which led to higher energy consumption and cost. This situation reinforces the importance of considering several factors, not only the yield of the motor-pump set, in energy efficiency analyses.

The characteristics of the centrifugal pumps analyzed in Table 3 were compared with the characteristics of the UFRGS WSS. The centrifugal pump that would meet the demands of the system was taken from the catalog of manufacturer A, line 1. The catalog characteristics were compared with the estimates made in this research for a discharge of $30 \mathrm{~m}^{3} / \mathrm{h}$, as presented in
Table 6. The estimated values and the catalog values presented a difference of $10 \%$ and $8 \%$ for the point of nominal discharge and nominal head, respectively. For the point of operation, the yield presented a difference of $4.5 \%$.

Another possibility of using Equations 9 and 10 is to evaluate the yield of the pump if the point of operation is altered by means of a decrease in the pumping discharge (valve bottleneck). To exemplify this situation, the operation of the current UFRGS WSS pump was calculated for a discharge of $30 \mathrm{~m}^{3} / \mathrm{h}$. The results obtained are shown in Table 7 and showed that there would be a 
Table 6. Comparison between the characteristics estimated and found in catalog.

\begin{tabular}{lccc}
\hline Pump & $\begin{array}{c}\text { Design } \\
\text { Estimate }\end{array}$ & Catalog & $\begin{array}{c}\text { Diference } \\
\mathbf{( \% )}\end{array}$ \\
\hline $\mathrm{Q}_{1 / 1}\left(\mathrm{~m}^{3} / \mathrm{h}\right)$ & 30.0 & 33.0 & 10.0 \\
$\mathrm{H}_{1 / 1}(\mathrm{~m})$ & 73.4 & 74.0 & 8.0 \\
$\eta \operatorname{máx~}(\%)_{\mathrm{Q}\left(\mathrm{m}^{3} / \mathrm{h}\right)}^{58.0}$ & 57.0 & 1.7 \\
$\mathrm{H}(\mathrm{m})$ & 30 & 30 & 0 \\
$\eta(\%)$ & 73.4 & 73.4 & 0 \\
\hline
\end{tabular}

Table 7. Example of the use of the equation for estimating the yield in points other than the PMY.

\begin{tabular}{lccccc}
\hline & $\begin{array}{c}\mathbf{Q} \\
\left(\mathbf{m}^{\mathbf{3}} / \mathbf{h}\right)\end{array}$ & $\mathbf{H}(\mathbf{m})$ & $\boldsymbol{\eta} \mathbf{( \% )}$ & $\mathbf{P}(\mathbf{k W})$ & $\begin{array}{c}\mathbf{E} \\
(\mathbf{k W h} / \mathbf{d})\end{array}$ \\
\hline PMY & 112.5 & 115 & 69.3 & 50.8 & 122.1 \\
Altered point & 30 & 138 & $32.8 \%$ & 34.4 & 309.8 \\
\hline
\end{tabular}

relative reduction of $48 \%$ between the yield in the PMY and the yield at the altered point of operation.

With the change in the discharge and the yield, the power in the axis and the operating time of the motor pump also change, so the energy consumed at the point altered by a bottleneck would be 2.5 times greater than the energy in the PMY.

\section{CONCLUSION}

The study on the performance of centrifugal pumps is of great importance for the analysis of the energy efficiency of pumping systems. From the research developed it was possible to conclude that:

- The centrifugal pump curves made dimensionless facilitated an understanding of its operation and enabled the extrapolation of the equations obtained in the case study;

- The mean maximum head of a centrifugal pump is 1.25 times greater than the nominal head;

- The variation of the yield as a function of the discharge is expressive for discharges below $60 \%$ or above $140 \%$ of the nominal discharge;

- Centrifugal pumps exhibit greater variation of the maximum yield for small specific rotation velocities, reaching better yields for Ns greater than or equal to 40 ;

- The dimensionless equations of head and yield are quadratic functions in relation to the dimensionless discharge variation;

- The dimensionless equations allow for estimations of the values of head, discharge and yield of centrifugal pumps in the design of WSS and the expected variation of these values at different points of operation.

\section{REFERENCES}

ALÉ, J. V. Sistemas fluido mecânicos: sistemas de pumpeamento. Porto Alegre: PUCRS, 2010.
ARUN SHANKAR, V. K.; UMASHANKAR, S.; PARAMASIVAM, S.; HANIGOVSZKI, N. A comprehensive review on energy efficiency enhancement initiatives in centrifugal pumping system. Applied Energy, v. 181, p. 495-513, 2016. http://dx.doi.org/10.1016/j. apenergy.2016.08.070.

BRASIL. Ministério das Cidades. Sistema nacional de informaçoes sobre saneamento: diagnósticos dos serviços de água e esgotos - 2015. Brasília: SNSA/MCIDADES, 2017.

CEEE - COMPANHIA ESTADUAL DE DISTRIBUIÇÃO DE ENERGIA ELÉTRICA. Tabela de tarifas: grupo A. Rio Grande do Sul: CEEE DISTRIBUIÇÃO, 2016. Available from: <http://www.ceee.com.br/pportal/ceee/archives/Tarifas/ Tarifas_Grupo_A_2016.pdf>.Access on: 16 nov. 2016.

COELHO, B.; ANDRADE-CAMPOS, A. G. A new approach for the prediction of speed-adjusted pump efficiency curves. Journal of Hydraulic Research, v. 54, n. 5, p. 586-593, 2016. http://dx.doi. org/10.1080/00221686.2016.1175521.

EIA - ENERGY INFORMATION ADMINISTRATION. International energy outlook 2016: report number DOE/EIA0484(2016). Washington: EIA, 2016. Available from: <http:// www.eia.gov/outlooks/ieo/world.cfm>. Access on: 22 dez. 2016.

EUROPEAN COMISSION. Study on improving the energy yield of pumps. United Kingdom: ETSU, 2001. Available from: < http:// www.watergymex.org/Watergy\%20Toolkit/resources/53_ Improving $\% 20$ Energy $\% 20$ Efficiency $\% 20$ of $\% 20$ Pumps.pdf $>$. Access on: 17 jan. 2017.

FREITAS, G. H. S.; MICHELS, F. S.; PASSOS, W. E. Análise adimensional e aplicação hidráulica do teorema Pi de Buckingham. Vetor, v. 25, n. 2, p. 84-101, 2015.

GOMES, H. (Org.). Sistemas de pumpeamento eficiência energética. João Pessoa: Universitária UFPB, 2009.

HENN, E. A. L. Máquinas de fluido. 3. ed. Santa Maria: UFSM, 2012.

INMETRO - INSTITUTO NACIONAL DE METROLOGIA, QUALIDADE E TECNOLOGIA. Tabelas de consumo/eficiência energética. 2002. Available from: <http://www.inmetro.gov.br/ consumidor/pbe/pbetab10.asp>. Access on: 20 nov. 2016.

KOOR, M.; VASSILJEV, A.; KOPPEL, T. Optimization of pump efficiencies with different pumps characteristics working in parallel mode. Advances in Engineering Software, v. 101, p. 69-76, 2016. http:/ / dx.doi.org/10.1016/j.advengsoft.2015.10.010.

MACINTYRE, A. J. Pumpas e instalações de pumpeamento. 2. ed. Rio de Janeiro: LTC, 2013.

SANTOS, S. L. Pumpas e instalações hidráulicas. São Paulo: LCTE, 2007.

TONIAL, F. Eficiência energética em estações de pumpeamento: estudo de caso do campus do vale da Universidade Federal Do Rio Grande 
Do Sul. 2014. 199 f. Dissertação (Mestrado em Recursos Hídricos e Saneamento Ambiental) - Instituto de Pesquisas Hidráulicas, Universidade Federal do Rio Grande do Sul, Porto Alegre, 2014. Available from: <http://hdl.handle.net/10183/114421>. Access on: 30 set. 2016.

WEG. Motor elétrico trifásico W22: catálogo técnico mercado brasileiro. 2016. Available from: <http://ecatalog.weg.net/files/wegnet/ WEG-w22-motor-trifasico-tecnico-mercado-brasil-50023622catalogo-portugues-br.pdf>. Access on: 16 nov. 2016.

WHITE, F. M. Mecânica dos fluidos. 4. ed. Rio de Janeiro: McGrawHill, 2002.

ZOCOLER, J. L.; HERNANDEZ, F. B. T.; SAAD, J. C. C.; CRUZ, R. L. Período de recuperação do investimento em pumpa hidráulica de melhor rendimento em sistemas de pumpeamento na tarifa horossazonal verde. Engenharia Agrícola, v. 31, n. 2, p. 290-302, 2011. http://dx.doi.org/10.1590/S0100-69162011000200009.

\section{Authors contributions}

Jóice Cristini Kuritza: Reviewed the data, contributed to the development of the curves, and developed the case study.

Giovani Camponogara: Performed the data collection on the pump curves and developed the equations and dimensionless curves.

Marcelo Giulian Marques: Guided the research.

Daniela Guzzon Sanagiotto: Guided the research.

Cristiane Battiston: Assisted in the development of the case study and guided research. 